\title{
沙冬青种子萌发及幼苗生长特性
}

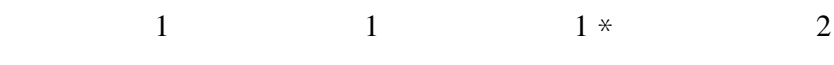 \\ （1 北京林业大学园林学院, 北京 100083）（2 中国林业科学研究院沙漠林业实验中心, 内蒙古自治区磴口县 015200)
}

摘 要 沙冬青 (Ammopiptanthus mongolicus) 是亚洲中部荒漠特有种,由于其分布的环境条件特殊 现存植被天然更 新困难，人工育苗、造林存在一定问题。为改善种皮透水性, 获得整齐一致的发芽, 分别用 21.5 (室温)、40、60、80 和 $90{ }^{\circ} \mathrm{C}$ 的温水浸种 5 min。结果表明 : $60{ }^{\circ} \mathrm{C}$ 温水浸种效果最好, 与对照相比, 显著地提高了种子发芽势,并有效地降 低硬实率。对比分析了 $15 、 20 、 25 、 30 、 35$ 和 $40{ }^{\circ} \mathrm{C}$ 环境温度下种子萌发的特性 种子发芽最适温度是 $30{ }^{\circ} \mathrm{C}$, 而胚根及 下胚轴伸长最快的温度为 $25 \sim 30{ }^{\circ} \mathrm{C}$ 。较低温度下种子发芽延续时间较长, 并且种子萌发后下胚轴和胚根伸长缓 慢, 易形成畸形(胚根严重扭曲、缢裂)幼苗。15 ${ }^{\circ} \mathrm{C}$ 时畸形幼苗占发芽种子数的 $28.1 \%$, 而 $30 \sim 40{ }^{\circ} \mathrm{C}$ 时仅占 $5.2 \%$ $8.6 \%$ 。温度过高不利于种子萌发及幼苗生长, $40{ }^{\circ} \mathrm{C}$ 时 吸胀种子绝大部分丧失活力 发芽种子在 $35{ }^{\circ} \mathrm{C}$ 以上温度下 生长 $2 \sim 3 \mathrm{~d}$, 胚根胚轴组织呈水渍状坏死。另外, 催芽后的种子播种在河沙中子叶出土最快, 出土率可达 $63 \%$, 显 著高于在粘质壤土中出土率 $(11 \%)$ 。不同粒径的种子播种后幼苗生长特性表现出一定的差异, 粒径 $5 \mathrm{~mm}$ 以下小 粒种子播种后幼苗长势弱, 苗期成活率低, 生长 $70 \mathrm{~d}$ 后幼苗成活率仅为 $35.4 \%$, 而粒径 $5 \mathrm{~mm}$ 以上种子同期幼苗成 活率达 $56.2 \%$ 。据上述试验结果 结合自然分布区内环境条件的资料, 分析了沙冬青濒危原因, 并为植被恢复育苗 措施提出建议。

关键词 沙冬青 浸种 温度 粒径 发芽率 幼苗出土

\section{SEED GERMINATION AND SEEDLING PERFORMANCE OF AMMOPIPTANTHUS MONGOLICUS}

\author{
DING Qiong ${ }^{1}$ WANG Hua ${ }^{1}$ JIA Gui-Xia ${ }^{1 *}$ and HAO Yu-Guang ${ }^{2}$ \\ (1 School of Landscape Architecture , Beijing Forestry University, Beijing 100083 , China) \\ (2 Desert Forestry Experimental Center, Chinese Academy of Forestry, Dengkou, Inner Mongolia 015200 , China)
}

\begin{abstract}
Background and Aims Ammopiptanthus monglicus, endemic to the semi-arid desert region of central Asia, is an endangered evergreen leguminous shrub. Having difficulties to recruit into its original habitat, A. mongolicus population is experiencing difficulties in regeneration, and the area it ever possessed is shrinking. It is included in the China Red Data Book of Endangered Plant as the third-class protected plant. Despite the importance of seed germination characteristics in developing an adequate understanding of both primary and secondary colonization processes, there still not a few previous studies on the germination of $A$. mongolicus. To get a comprehensive understanding about the germination characteristics and seedling performance of $A$. mongolicus , experiments were , therefore, conducted to define the optimum environmental condition for germination. Further, the seed size effects on the seedling performance is also investigated here.

Methods In order to find out optimal temperature for soaking, Seeds were soaked in water of 21.5 ( room temperature) , $40,60,80,90{ }^{\circ} \mathrm{C}$ for 5 minutes respectively. Treated seeds were placed on moistened filter papers in $11 \mathrm{~cm}$ diameter Petri dishes, then, transferred into a laboratory incubator at $28{ }^{\circ} \mathrm{C}$. To test the germination response of the seed to the environmental temperature, seeds presoaked in $60{ }^{\circ} \mathrm{C}$ hot water were put into incubator under $15,20,25,30,35,40{ }^{\circ} \mathrm{C}$ for germination, respectively. In the case of container seedling culture, presoaked seed were sowed with different cultural media, sandy soil , clay loam , mixed soil ( sand soil mixed with clay loam at the ratio of 1:1). Attempt to answer the question that whether the seeds with different size will differ in seedling performance, seeds were categorized into three groups according to the their diameter, those less than $5 \mathrm{~mm}$, those between 5 and $6 \mathrm{~mm}$, and those that of more than $6 \mathrm{~mm}$. Pretreated seeds of its respective size were sowed into the raised seedbed separately. Observations on the seedlings survival rate, leaf width, leaf number, and plant height were recorded almost twice a month.
\end{abstract}

Key Results Seeds presoaked in water at $60{ }^{\circ} \mathrm{C}$, gave the highest germination vigor that $56.4 \%$ seeds were 
germinated within one day' s incubation at $28{ }^{\circ} \mathrm{C}$. The optimal temperature for hypocotyl and radicle elongation of seedling is $25{ }^{\circ} \mathrm{C}$ to $30{ }^{\circ} \mathrm{C}$, lower than that for seed germination initiation $\left(30{ }^{\circ} \mathrm{C}\right.$ ). Temperature above $40{ }^{\circ} \mathrm{C}$ would likely have a detrimental effect on seedling growth in the germination test, it cause the hypocotyl and radical tissue damage and eventually decay of the seedlings. Interestingly , the percentage of abnormal seedlings with tightly twisted radicle and split tip , which are less likely to survive in the seedbed, were just $5.2 \%-8.6 \%$ under the temperature of $30{ }^{\circ} \mathrm{C}$ to $40{ }^{\circ} \mathrm{C}$, greatly less than that of $28.1 \%$ under the temperature of $15{ }^{\circ} \mathrm{C}$. In the case of container seedling culture, sixty three percent seedlings emerged out of the sand soil within 7 days, while in clay loam only $11 \%$. Compared with seedlings emerged from the smaller one, seedlings emerged from seeds with size more than $5 \mathrm{~mm}$ tend to be stronger and growing more vigorous than the smaller one during the early stages of growth. This trend is further evidenced by the weak and high susceptibilities to pathogen and continuous death of seedlings from the smaller seeds within the 70 days growth. Seedlings from larger seeds took only about 57 days to attain a constant survival rate of more than $56.3 \%$, while seedlings from the smaller ones took more than 70 days to attain $35.4 \%$ and still on a decreasing trend.

Conclusions Extremely high or low temperature have a detrimental effect on germination and seedlings performance of $A$. mongolicus shortly after the germination initiation , despite the fact that their adult counterpart have a extremely high tolerance to the hardness of its environment. This is accordance with our filed observation that very few seedlings or saplings were seen in the natural habitat. Soaking in hot water between $40{ }^{\circ} \mathrm{C}$ to $60{ }^{\circ} \mathrm{C}$ did promote the germination rate of $A$. mongolicus , and decrease the percentage of remaining hard-coated seeds. Seeds less than $5 \mathrm{~mm}$ in diameter showed reductions in seedling quality and seedling performance suggests that seeds with different size may have significant impacts on future community composition in the prospect habitat and should be treated discriminatingly in nursery and re-introduction activity.

Key words Ammopiptanthus mongolicus, Soaking, Temperature, Germination percentage, Seed size , Seedling emergence

沙冬青 (Ammopiptanthus mongolicus) 属于豆科蝶 形花亚科沙冬青属, 又称蒙古黄花木,为第三纪子遗 种, 是亚洲中部荒漠地区特有常绿阔叶灌木, 由于其 突出的抗寒、抗旱、耐盐碱特性, 而成为研究植物抗 逆机制和获得抗性基因的重要材料。( 费云标等, 1994 ZZhao \& Wang 2002)。目前 沙冬青天然种群趋 于老化, 群落分布面积日趋缩小, 被国家列入第一批 珍稀濒危保护植物名录, 成为国家三级重点保护植 物、内蒙古二级重点保护植物。刘家琼等 (1995) 和 刘果厚 (1998) 曾对沙冬青群落作过专门调查, 并根 据沙冬青原产地生态环境条件, 分析探讨了沙冬青 濒危机制, 认为在分布区野外条件下落地种子不易 获得适宜生长发育条件、繁殖材料的缺乏以及分布 区生态环境恶化是造成种群老化的重要原因。沙冬 青以种子繁殖为主, 种子萌发对环境条件的要求反 映了该物种自身遗传特性及适应环境的能力,由种 子到幼苗形成这一阶段是种群内个体更新、物种得 以繁衍的关键性环节。

然而至今还没有关于沙冬青萌发及幼苗生长特 性的报道。杨期和等(2004)报道了沙冬青属的另一 个物种矮沙冬青 (Ammopiptanthus nanus) 种子萌发特 性。指出矮沙冬青种子萌发对环境条件有较宽的适 应范围, 但是在幼苗出土及幼苗期生长环节较为脆 弱, 导致幼苗成活率较低。沙冬青与矮沙冬青在分
布区范围、遗传及生物学特性等方面均存在一定差 异, 因此, 系统地研究沙冬青种子萌发及幼苗生长对 环境条件的响应, 有利于明确界定沙冬青种子萌发 及幼苗生长适宜的环境条件, 为不同引种地区采取 合理的育苗措施提供参考。本文进一步结合沙冬青 分布区实地调查结果及有关资料, 分析野外条件下 限制沙冬青种子萌发的主要环境因子, 将有助于探 讨沙冬青种群濒危机制。

\section{1 材料和方法}

\section{1 种子采集地概况及种子特性}

种子采集地为内蒙古磴口县 地理位置为 $40^{\circ} 13^{\prime}$ $\mathrm{N}, 107^{\circ} 05^{\prime} \mathrm{E}$ 。该区年平均气温 $7.9{ }^{\circ} \mathrm{C}$, 无霜期 $169 \mathrm{~d}$, 年平均降水量 $149.2 \mathrm{~mm}$, 年平均蒸发量 $2380.6 \mathrm{~mm}$, 年平均相对湿度 $46 \%$ 。常见的植物有： 霸王 (Zygophyllum xanthoxylum)、沙冬青、油蒿 (Artemisia ordosica) ,以及白刺 (Nitraria tangutorum)、 猫头刺 (Oxytropis aciphylla) 和四合木 ( Tetraena mongolica)。

于 2002 年 7 月底至 8 月初采集种子,种子依次 过 5 和 $6 \mathrm{~mm}$ 孔径金属网篮, 粒径 $<5 \mathrm{~mm}$ 种子占 $51.13 \%$, 粒径 5 6 $\mathrm{mm}$ 种子占 $42.12 \%$ 粒径 > $6 \mathrm{~mm}$ 种子占 $0.54 \%$, 杂质占 $6.21 \%$ 。种子千粒重为 $(44.04 \pm 1.47) \mathrm{g}$ 。前期的试验结果表明由粒径 $<5$ 
$\mathrm{mm}$ 的种子长成的幼苗成活率较低, 因此, 除研究不 同粒径种子成苗特性外 均采用粒径为 5 6 mm 的 种子。

\section{2 不同水温浸种对种子萌发的影响}

处理所用的水温分别为 $90 、 80 、 60 、 40$ 和 $21.5{ }^{\circ} \mathrm{C}$ (CK 室温);每种处理的种子数为 50 粒 (3 次重复)。 干种子用 $70 \%$ 酒精消毒 $3 \mathrm{~min}$ 后，用无菌水清洗干 净, 再以 $2 \%$ 的次氯酸钠溶液浸泡 $10 \mathrm{~min}$ 并清洗 3 4 次。将盛 $300 \mathrm{ml}$ 蒸馏水的烧杯置于水浴锅内加热 至所需温度 将种子放入烧杯中, 保持相应的温度 5 $\min$ 后 取出烧杯并立即倒掉热水，加入凉水使水温 迅速下降至室温。灭菌后的培养血中铺两层灭菌滤 纸, 向培养血中加水 $2 \mathrm{~mm}$ 深, 经浸种处理的种子排 放在滤纸上, 置于每天光照时间长 $14 \mathrm{~h} 、 28{ }^{\circ} \mathrm{C}$ 人工 气候室中。每天统计 1 次发芽 (胚根伸出种孔长达 $2 \mathrm{~mm}$ ) 种子数, 并换水 1 次, 试验结束统计 1 次硬实 率。

\section{3 不同环境温度对种子萌发及胚根伸长的影响}

基于前一试验结果, 按上述方法种子经 $60{ }^{\circ} \mathrm{C}$ 水 温浸种处理后, 放入垫有滤纸并经灭菌处理的培养 皿中,每血 50 粒种子, 3 次重复,分别在 $15 、 20 、 25$ 、 $30 、 35$ 和 $40{ }^{\circ} \mathrm{C}$ 人工培养箱中恒温培养, 每天统计 1 次发芽的种子数, 并定期测量各种温度下幼苗胚根 长度。

\section{4 不同基质中幼苗出土情况}

在容器育苗条件下,采用 3 种不同基质: $\mathrm{a}$. 河 沙、b.粘质壤土、c.河沙与粘质壤土按 $1: 1$ 混合 $(3$ 种基质的松散程度为 $: a>c>b$ ）播种经催芽后的种 子, 定期统计幼苗出土情况。

\section{5 不同粒径种子成苗特性}

将粒径小于 $5 \mathrm{~mm} 、 5 \sim 6 \mathrm{~mm}$ 和大于 $6 \mathrm{~mm}$ 种子， 经 $60{ }^{\circ} \mathrm{C}$ 温水催芽处理后, 按 $10 \mathrm{~cm} \times 10 \mathrm{~cm}$ 株行距将 催芽后的种子露地播种于面积为 $1.0 \mathrm{~m} \times 1.0 \mathrm{~m}$ 苗 床, 采用随机区组设计 ( 3 次重复)。播种后定期统 计幼苗存活数、苗高、叶数和叶宽。试验地点为北京 林业大学苗圃, 土壤为沙壤土, 速效磷含量为 170 $\mathrm{mg} \mathrm{L}^{-1}$,速效钾为 $85.88 \mathrm{mg} \mathrm{L^{-1 }}$, 有机质含量为 $2.43 \%$ ，全 $\mathrm{N}$ 含量为 $0.0929 \%, \mathrm{pH}$ 值为 8.54 。根据 前述种子萌发特性研究结果及北京地区气候条件， 本试验播种时间是在 8 月中旬, 苗床采用 $30 \mathrm{~cm}$ 高 床。

\section{6 数据处理}

收集数据用 SPSS 软件 (SPSS13.0 for windows), 采用 ANOVA 进行显著性分析。

\section{2 结果与分析}

\section{1 不同水温浸种对种子萌发的影响}

采用不同的水温浸种 结果显示, 热水浸泡种子 可以增加种皮透水性, 促进种子吸水膨胀，从而有效 降低硬实率。60 ${ }^{\circ} \mathrm{C}$ 以上温水浸种处理后硬实存留的 百分率低于 $2.54 \%$,与对照 $\left(21.5{ }^{\circ} \mathrm{C}\right.$, 室温, 硬实存留 百分率 $7.10 \%$ ) 相比差异显著 $(p<0.05)$ (图 1)。

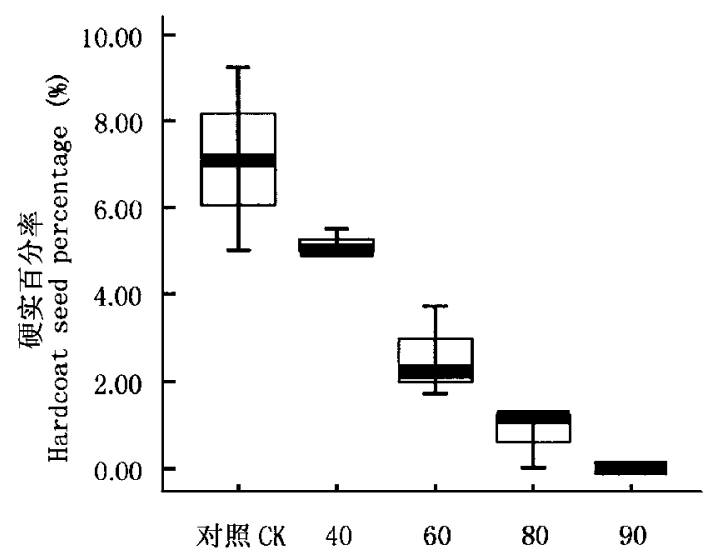

漫种温度 Soaking temperature $\left({ }^{\circ} \mathrm{C}\right)$

图 1 浸种水温对消除硬实的效果

Fig. 1 The effect of soaking water temperature on the hard-coated seeds

图 2 显示, 试验结束时 经 40 和 $60{ }^{\circ} \mathrm{C}$ 温水浸处 理种子,发芽率分别为 $60.1 \%$ 和 $63.2 \%$,与对照 $(54.3 \%)$ 相比,差异均不显著 $(p>0.05)$ 。尽管如 此，以适当的水温浸种能有效地提高种子发芽势。 $60{ }^{\circ} \mathrm{C}$ 水温浸种后,种子在两天以内集中发芽,发芽 率为 $52.2 \%$,与对照 $(36.2 \%)$ 差异达显著水平 $(p<$ $0.05)$,相比之下 $40{ }^{\circ} \mathrm{C}$ 处理 ( $\left.45.9 \%\right)$ 与对照差异不 显著 $(p>0.05)$ 。然而, 浸种处理水温过高容易导致 种子活力降低而影响种子发芽。 $80^{\circ} \mathrm{C}$ 处理虽能有

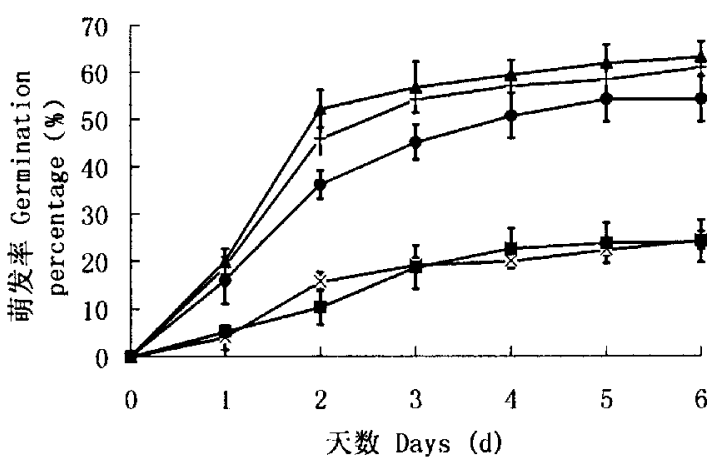

$\rightarrow$ 对照 $\mathrm{CK}-1-40^{\circ} \mathrm{C}-460^{\circ} \mathrm{C}-x-80^{\circ} \mathrm{C}-90^{\circ} \mathrm{C}$

图 2 不同温度浸种对种子萌发影响

Fig.2 Seed germination after soaked in water under different temperature 
效地降低硬实率，但是浸种后大部分种子丧失活力， 试验结束时发芽率仅为 $24.4 \%$ 。

\section{2 不同环境温度对种子萌发的影响}

经浸种处理后的种子, 在 $15{ }^{\circ} \mathrm{C}$ 条件下, 到第二 天才开始有少量发芽, 并且在测试时段内没有表现 明显发芽高峰期, 发芽率为 $45.7 \%$, 测试结束后还 有部分种子陆续萌发。当环境温度为 20 和 $25{ }^{\circ} \mathrm{C}$ 时, 分别有 $45.5 \%$ 和 $52.3 \%$ 种子在两天内集中萌 发 测试结束时发芽率分别为 $57.0 \%$ 和 $63.2 \%$ 。在 $30{ }^{\circ} \mathrm{C}$ 条件下, $56.4 \%$ 的种子能在第一天内集中萌 发, 发芽势较强, 测试结束时, 发芽率达 70.1\%。 $35{ }^{\circ} \mathrm{C}$ 条件下, 种子发芽集中于第一天，达 $38.4 \%$,但 是, 在这以后只有极少量种子陆续萌发, 最终发芽率 仅为 $46.1 \%$, 当环境温度上升到 $40{ }^{\circ} \mathrm{C}$ 时, 只有 $18.6 \%$ 种子能萌发, 大部分种子丧失活力 (图 3)。

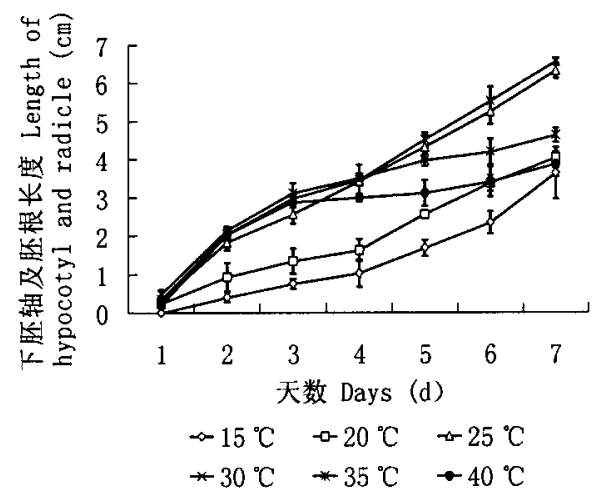

图 3 不同环境温度对胚根伸长影响

Fig.3 Effect of different temperature on radical elongation

较低环境温度下, 沙冬青幼苗胚根及下胚轴伸 长缓慢。种子萌发 $4 \mathrm{~d}$ 后, 在 15 和 $20{ }^{\circ} \mathrm{C}$ 环境条件 下, 胚轴和胚根总长仅分别为 1.02 和 $1.62 \mathrm{~cm}$, 而 25 和 $30{ }^{\circ} \mathrm{C}$ 条件下, 分别为 3.42 和 $3.45 \mathrm{~cm}$ 。随后胚根 胚轴伸长速度加快, 到第七天时, 15 和 $20{ }^{\circ} \mathrm{C}$ 条件 下, 胚根与下胚轴长度分别为 3.64 和 $4.65 \mathrm{~cm}$, 与同 期 25 和 $30{ }^{\circ} \mathrm{C}$ 时 (分别为 6.32 和 $6.56 \mathrm{~cm}$ ) 相比差异 极显著 $(p<0.01)$ 。35 和 $40{ }^{\circ} \mathrm{C}$ 条件下, 下胚轴和胚 根伸长速度在前 $3 \mathrm{~d}$ 较快, 与 25 和 $30{ }^{\circ} \mathrm{C}$ 时伸长速度 没有明显差异, 但随着时间的推移, 伸长速度逐渐减 缓(图 4) , 此时, 大部分幼苗胚根和胚轴组织出现水 渍状坏死并腐烂, 最终导致幼苗死亡。这与不同温 度下种子发芽情况相一致, 即温度过高大部分种子 丧失活力 组织染病死亡。

不同温度下萌发试验结果还表明 环境温度过 低 种子萌发后, 幼苗容易产生畸形, 表现为胚根严 重扭曲, 扭曲部位胚根通常伴有深度横裂(图 5), 这
类幼苗在后期往往生长不良或不能正常生长。15 ${ }^{\circ} \mathrm{C}$ 条件下畸形幼苗占萌发种子数的 $28.1 \%$ 。而 $30 \sim 40{ }^{\circ} \mathrm{C}$ 条件下畸形幼苗仅占发芽种子数的 $5.2 \% \sim 8.6 \%$ (图 6)。

\section{3 不同介质对幼苗出土及生长的影响}

催芽后的沙冬青种子在河沙中幼苗出土最快， 播种后第七天出土率达到 $62.9 \%$ 并趋于稳定 ;而在 粘质壤土中 幼苗出土缓慢, 直到播种后第十天幼苗 出土率才达到最高值 $11.1 \%$, 二者之间差异达显著 水平 $(p<0.05)$ 。河沙与粘质壤土混合介质幼苗出 土情况介于二者之间 幼苗出土率为 $16.7 \%$ (图 7)。

\section{4 不同粒径的种子幼苗生长特性}

不同粒径的种子播种出苗后, 经过 $70 \mathrm{~d}(10$ 月 21 日)的生长, 试验结果表明, 幼苗株高、叶片数及 叶宽与种子的粒径大小密切相关。粒径 > $6 \mathrm{~mm}$ 、粒 径 5 6 $\mathrm{mm}$ 及粒径 $<5 \mathrm{~mm}$ 种子长成幼苗后, 各自在 株高及叶片数上都具有显著差异。从叶片宽度来 看, $5 \mathrm{~mm}$ 以上的种子与 $5 \mathrm{~mm}$ 以下的种子差异达到

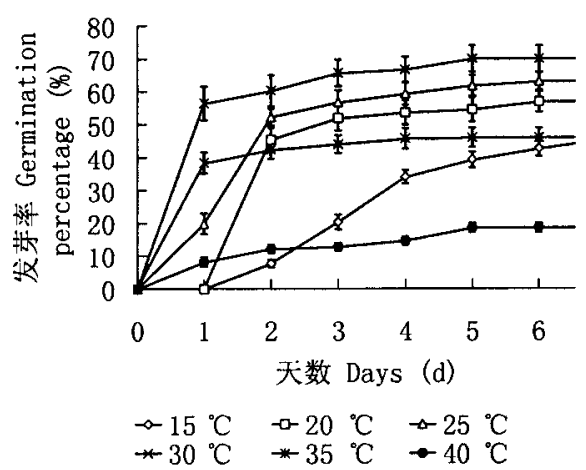

图 4 不同温度下种子萌发动态

Fig.4 Germination dynamics of seeds under different temperature

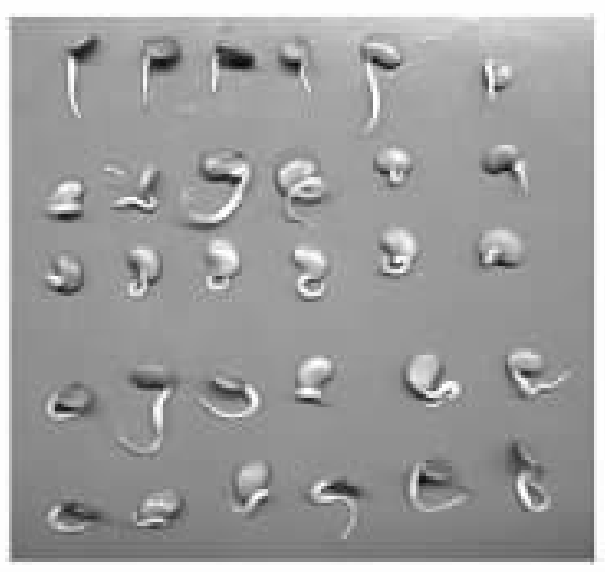

图 5 沙冬青正常幼苗(第一行)和畸形幼苗形态 Fig.5 The shape of normal (first row) and abnormal seedlings of Ammopiptanthus mongolicus 


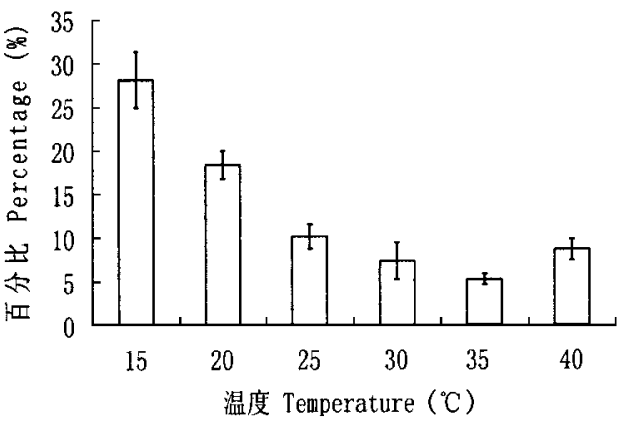

图 6 不同温度条件下畸形幼苗占萌发种子数的比例 Fig. 6 The percentage of abnormal seedling among the germinated seed under different temperature

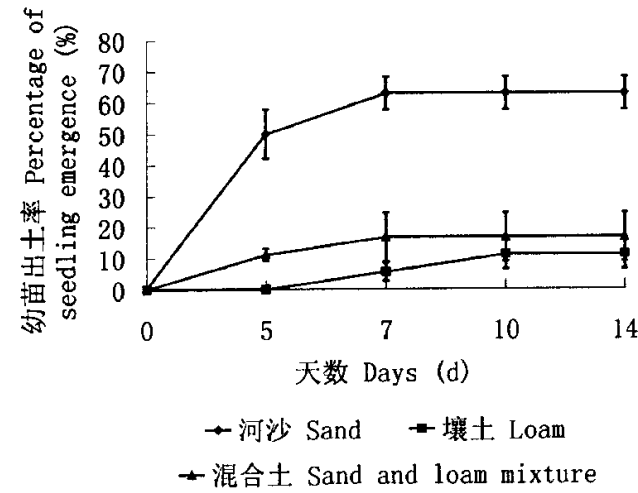

图 7 不同介质对幼苗出土影响

Fig. 7 Seedlings emergence under different substrates

显著水平, 而粒径 $6 \mathrm{~mm}$ 以上种子和粒径 $5 \sim 6 \mathrm{~mm}$ 种子之间差异不显著(表 1 )。

表 1 幼苗生长与种子粒径的关系

Table 1 The relationship between seedling growth and seed size

\begin{tabular}{cccc}
$\begin{array}{c}\text { 种子粒径 } \\
\text { Seed size }\end{array}$ & $\begin{array}{c}\text { 株高 } \\
\text { Plant height }(\mathrm{cm})\end{array}$ & $\begin{array}{c}\text { 叶片数 }(\text { 个) } \\
\text { Leaf number }\end{array}$ & $\begin{array}{c}\text { 叶宽 } \\
\text { Leaf width }(\mathrm{cm})\end{array}$ \\
\hline $6 \mathrm{~mm}$ & $4.17^{\mathrm{a}}$ & $9.15^{\mathrm{a}}$ & $1.30^{\mathrm{a}}$ \\
$5-6 \mathrm{~mm}$ & $3.22^{\mathrm{b}}$ & $8.19^{\mathrm{b}}$ & $1.19^{\mathrm{a}}$ \\
$<5 \mathrm{~mm}$ & $1.93^{\mathrm{c}}$ & $5.92^{\mathrm{c}}$ & $0.93^{\mathrm{b}}$ \\
\hline
\end{tabular}

$L S D \alpha=0.05$ 相同编号表明差异不显著 Same letters denote no significant differences between groups

幼苗对环境适应能力具有一定的差异。在最初 的一个月以内，各粒径所对应幼苗都具有较高的死 亡率 幼苗存活率无显著差异 $(p>0.05)$ 。然而, 幼 苗生长一个月以后, 由粒径 $5 \mathrm{~mm}$ 以下种子长成幼 苗对环境适应能力仍然较差, 保持较高的幼苗死亡 率; 而粒径 $5 \mathrm{~mm}$ 以上种子长成的幼苗较为健壮, 随 幼苗组织木质化程度增加 ,抗病能力加强 幼苗死亡 数减少, 生长 $60 \mathrm{~d}$ (10 月 11 日) 以后, 成活率保持稳 定。到第七十天时，幼苗成活率稳定在 $56.2 \%$ 以上 (图 8) 与粒径 $5 \mathrm{~mm}$ 以下的种子 $(35.4 \%$ ) 相比, 差异 达到显著水平 $(p<0.05)$ 。

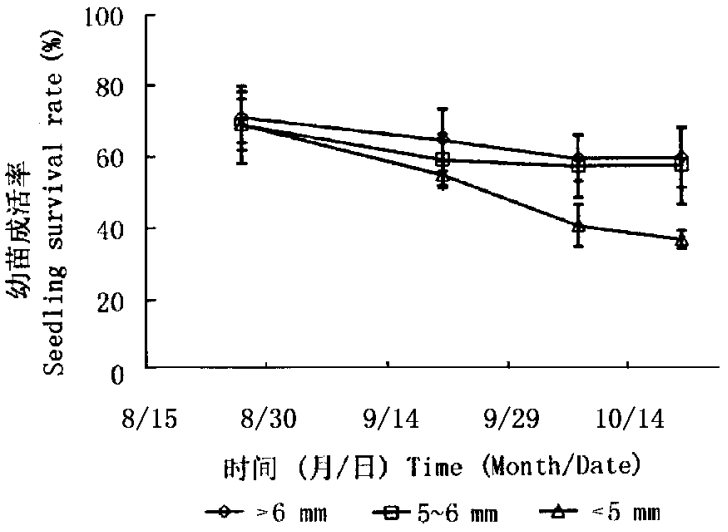

图 8 不同粒径种子幼苗成活

Fig. 8 The survival rate of seedlings from different sized seeds

\section{3 讨 论}

沙冬青种子种皮革质, 表面被蜡质, 在一定程度 上影响种子对水分的吸收,多数种子浸种后能在 $24 \mathrm{~h}$ 内吸水膨胀, 但部分种子经长期浸泡, 仍不能吸 水膨胀而保持硬实状态。这些硬实种子的形成对种 的繁衍是一种非常有利的特性。即种子散落后, 随 外界条件的影响而逐渐改变种皮透性，由于种皮透 性的差异, 同一批种子落入土中, 能在不同年份内陆 续出苗, 因而增加其繁衍种族的可能性(叶常丰和戴 心维,1994)。但是，引种育苗过程中却力求降低硬 实率, 使其在短时间内集中萌发, 从而获得整齐一致 的幼苗。温水浸种可以增进沙冬青种皮透水性，促 进种子吸水膨胀，提高种子发芽势。但是浸种水温 过高会导致种子丧失活力, 表现为种子只能吸水膨 胀而不能萌发。本试验以 $60{ }^{\circ} \mathrm{C}$ 温水浸种, 有效地改 善了沙冬青种皮透水性，并显著提高种子发芽势，在 育苗中, 这将有利于出苗整齐便于管理。值得注意 的是, 浸种处理的效果是水温与浸种时间综合作用 的结果, 当浸种水温偏高时, 处理时间宜短, 反之处 理时间应稍长。

较高的环境温度 $\left(30{ }^{\circ} \mathrm{C}\right.$ 左右) 有利于沙冬青种 子发芽及胚根和下胚轴伸长, 有学者认为这是沙冬 青热带起源的又一证据。沙冬青种子萌发最适温度 为 $30{ }^{\circ} \mathrm{C}$, 稍高于胚根和下胚轴伸长的最适温 (25 $\left.30{ }^{\circ} \mathrm{C}\right)$ 。下胚轴和胚根的伸长速度决定了幼苗子叶 出土的时间 种子催芽播种后, 如果子叶不能及时出 土而滞留在土中的时间过长, 含水量较高的根茎及 肥厚子叶容易发生腐烂,引发病害, 导致个体死亡。 $20{ }^{\circ} \mathrm{C}$ 以下的较低温不利于种子萌发及幼苗出土。

除此以外，低温与畸形幼苗形成的关系较密切， 
畸形幼苗表现为胚根严重扭曲反转, 甚至打成结状。 扭曲的胚根和下胚轴在土壤中需要较长时间调整生 长方向, 而使子叶不能及时出土。在扭曲最严重的 局部区域，胚根表面通常具有不同深浅程度的横向 缢裂。这类裂口将增加土传病原菌浸染的风险, 可 能是幼苗在初期阶段容易感染病害、导致较高死亡 率的一个重要原因。然而, 过高的环境温度也不利 于沙冬青种子萌发及幼苗生长。本试验结果表明 : $35{ }^{\circ} \mathrm{C}$ 以上环境温度严重削弱了种子活力, 大部分种 子在 $40{ }^{\circ} \mathrm{C}$ 温度下快速丧失活力。已经萌发的种子， 其幼苗的胚根和胚轴组织相继出现水渍状坏死并腐 烂, 最终导致幼苗死亡。干种子吸足水分后, 胚和胚 乳细胞的原生质由凝胶态变为溶胶态, 细胞内的各 种酶活化, 催化体内各种生理生化反应, 生命活动加 强环境温度过高会导致幼苗体内酶钝化，呼吸作用 受抑制, 而种子活力下降。种子萌发后 较高温度会 导致脂类过氧化, 而使细胞膜受到伤害 (Bhattacharjee \& Mukherjee, 1998 ; Scandalios et al . 2000)。

种子萌发过程中通过有氧呼吸, 分解种胚咜存 养分并释放能量, 供给各项生理活动, 因而需要充足 的氧气供应。苗床介质的透气性直接影响到其氧气 供应能力, 与粘质壤土相比, 河沙透气性最好, 质地 疏松 幼苗出土过程中受到阻力也相对较小, 当水分 和温度适宜的条件下, 河沙中幼苗出土最快最整齐。 粘质壤土在浇水或雨后, 含水量增加, 通气能力下 降, 并易板结 经催芽的沙冬青在粘质壤土中出土最 慢。

双子叶植物种子萌发后, 幼苗早期主要靠吸收 子叶中咜存的养分来维持生长, 因此, 咜存养分多的 种子幼苗长势健壮, 抗逆性强。种子粒径大小在一 定程度上体现了种子咜存养分的多少。一般来说， 大粒种子比同一植株上的小粒种子具有更充足的起 始物质, 活力较高, 长出的幼苗健壮。粒径 $5 \mathrm{~mm}$ 以 下的种子 幼苗早期生长从外观上来看: 株高、叶片 数、叶宽均显著低于 $5 \mathrm{~mm}$ 以上的大粒种子。它们 之间对环境的适应能力也具有差异, 粒径 $5 \mathrm{~mm}$ 以 下种子形成的幼苗长势弱, 易受病虫危害 幼苗成活 率显著低于 $5 \mathrm{~mm}$ 以上的种子。因此, 在原产地或 异地引种育苗时, 粒径 $5 \mathrm{~mm}$ 以下的种子不宜用于 育苗, 如果要用于育苗, 应单独加以精细管理, 才可 能获得较高的幼苗成活率。出土生长 $40 \sim 60 \mathrm{~d}$ 以 内沙冬青幼苗组织含水量高, 对环境条件反应较敏 感,容易受病害侵染而导致较高的死亡率。

自然分布区沙冬青群落花期从 4 月中旬到 5 月
初, 果实成熟期在 7 月下旬到 8 月中旬 种子成熟后 极易从扁平的荚果中散落。环境中的水热条件组合 决定了沙冬青成熟种子落地后的命运(暂不考虑生 物因子影响)。沙冬青种子出土能力弱, 种子埋藏深 度 $10 \mathrm{~cm}$ 以上出土困难, 而即使在 $25 \sim 30{ }^{\circ} \mathrm{C}$ 的最适 条件下 种子发芽生长 $7 \mathrm{~d}$ 后, 胚根和下胚轴总长度 也仅能达到 $6 \sim 7 \mathrm{~cm}$ 。因此, 分析水分和温度对种子 萌发的影响时, 表层土壤水分及土温的影响最大。

环境中具有充足的水分供给干种子吸胀，才能 启动种子萌发。荒漠地区地表蒸发量在 $2000 \mathrm{~mm}$ 以上, 而年平均降水量仅 $200 \mathrm{~mm}$ 左右, 蒸发量极度 高于降水量使表土极为干旱, $0 \sim 15 \mathrm{~cm}$ 范围内表土 含水量常在 $1 \% \sim 2 \%$, 远不能满足种子吸水膨胀的 要求。在荒漠地区缺少内陆河流，地下水对埋藏在 土壤表层的种子吸水膨胀也不具有明显意义，因而， 种子成熟落地以后, 特定时段的集中降雨才能为种 子的萌发提供机遇。据王新平等 (2003) 资料 :当平 均降水强度为 $1.5 \mathrm{~mm} \mathrm{~h}^{-1}$ 连续降水 $26 \mathrm{~h}$, 累积降水 量达 $38.9 \mathrm{~mm}$ 时, 降雨结束时, 土表 $0 \sim 10 \mathrm{~cm}$ 沙层 土壤含水量可达到 $8 \%$ 左右。荒漠地区的降雨集在 6 9 月, 因而种子成熟落地后开始直到 9 月这段时 间, 是种子获得充足水分吸水膨胀的最佳时期。然 而, 我们的研究结果表明从种子发芽到生长 $1 \sim 2$ 个 月内沙冬青幼苗对环境温度响应较为敏感, 环境温 度低于 $20{ }^{\circ} \mathrm{C}$ 时, 沙冬青种子萌发极慢, $30 \sim 35{ }^{\circ} \mathrm{C}$ 时 萌发最快, 当温度上升到 $40{ }^{\circ} \mathrm{C}$ 时大部分种子丧失活 力而不能萌发, 幼苗没有形成真叶以前, 35 40 ${ }^{\circ} \mathrm{C}$ 以上的高温容易导致其下胚轴及胚根组织受到损伤 甚至死亡。据崔向慧等 (2003) 资料整理 :在民勤荒 漠绿洲过渡区 距地表 $5 \mathrm{~cm}$ 处沙层温度日变化情况 是 .9月 温度高于 $35{ }^{\circ} \mathrm{C}$ 以上的时段分别为 $9 \sim 17$ 点 (共 $9 \mathrm{~h}$ ) 温度高于 $40{ }^{\circ} \mathrm{C}$ 以上的时段分别为 $10 \sim 15$ 点 $(6 \mathrm{~h})$, 夜间最低温度不低于 $17{ }^{\circ} \mathrm{C} ; 10$ 月, 30 和 40 ${ }^{\circ} \mathrm{C}$ 以上高温时段减少, 分别发生在 :12:00 16:00 (5 h) ,13:00 15:00 (3h) 低于 $15{ }^{\circ} \mathrm{C}$ 。从当地 7 10 月 对应月平均气温情况来看 $: 7 \sim 8$ 月是全年温度最高 时期, 分别为 30.8 和 $25.0{ }^{\circ} \mathrm{C}$, 而 $9 、 10$ 月仅分别为 19.9 和 $12.0{ }^{\circ} \mathrm{C}$ 。由这一变化趋势可以推知, 7 8 月, 距地表 $5 \mathrm{~cm}$ 处 $35{ }^{\circ} \mathrm{C}$ 以上的高温时段要长于 $9 \mathrm{~h}$ (9 月 ) $40{ }^{\circ} \mathrm{C}$ 以上的高温时段长于 $6 \mathrm{~h}$, 并且, 白天极 端最高温度和夜间最低温度远远高于 9 月所能达到 的温度。所以 种子落地后, 即使能满足干种子吸水 对土壤含水量的要求, 仅就环境温度而言, 7 9 月 荒漠地区表土白天大多数时间处于 $35 \sim 40{ }^{\circ} \mathrm{C}$ 极度 
高温，对发芽后的种子以及尚处于子叶期的幼苗造 成伤害, 不利于幼苗成活, 可能是限制天然分布区沙 冬青种群更新的一个重要因素。

种子发芽率、幼苗子叶能否及时出土、畸形幼苗 所占比例均关系到育苗、造林成苗率, 因此, 在人工 恢复或重建沙冬青植被以及育苗过程中, 应综合考 虑种子萌发的各环节对环境条件的要求, 合理采取 相应成套措施以提供最佳的种子萌发及幼苗生长环 境条件。有关沙冬青引种栽培的报道主要集中在原 产地或邻近地区, 这些地区进行沙冬青的育苗时, 为 了降低空穴百分率, 通常在苗床或容器中每穴播种 $2 \sim 3$ 粒已催芽的种子 (王继林等, 2000) , 有的甚至达 $5 \sim 8$ 粒 (张涛和将志荣, 1987)。相比之下 预先淘汰 直径 $5 \mathrm{~mm}$ 以下的种子, 每穴播种/粒经催芽的种 子, 既节约种子用量, 又能减少间苗及空杯补苗等人 工费用。沙冬青引种育苗成活率低一直是其植被恢 复及物种利用的一个主要限制因子。本研究结果明 确界定了沙冬青种子萌发及幼苗生长适宜的环境条 件, 为不同引种地区采取合理育苗措施提供参考。

\section{参 考 文 献}

Bhattacharjee S, Mukherjee AK ( 1998) . The deleterious effects of high temperature during early germination on membrane integrity and subsequent germination of Amaranthus lividus. Seed Science Technology, 22, $1-8$.

Cui XH(崔向慧), Wang B(王兵), Gao ZH(高志海), Ji YF(纪 永福) (2003). Research on change characteristics of sandy soil temperature at the transitional zone of oasis desert in Minqin. Scientia Silvae Sinicae (林业科学), 16,708-714. (in Chinese with English abstract)

Fei YB(费云标), Sun LH(孙龙华), Huang T(黄涛), Shu NH(舒 念红), Gao SQ (高素琴), Jian LC(简令成) (1994). Isolation and identification of antifreeze protein with high activity in $A m$ mopiptanthus mongolicus. Acta Botanica Sinica (植物学报), 36,
649 - 650. (in Chinese with English abstract)

Scandalios JG, Acevedo A, Ruzsa S (2000). Catalase gene expression in response to chronic high temperature stress in maize. Plant Science, 156, $103-110$.

Liu GH(刘果厚) (1998). Study on the endangered reasons of Ammopiptanthus mongolicus in the desert of Alashan. Bulletin of Botanical Research (植物研究) , 18,341 - 345. (in Chinese with English abstract)

Liu JQ(刘家琼), Qiu MX(邱明新), Yang K(杨 $\square$ ), Shi QH(石 庆辉) (1995). Studies on the plant community of Ammopiptanthus mongolicus . Journal of Desert Research (中国沙漠) , 15, 109 - 115. (in Chinese with English abstract)

Wang JL(王继林), Guo ZZ(郭志中), Yu HB(于洪波), Wang SY (王三英), He HL(何虎林) (2000). Comparative trial of 4 cultivating seedlings methods for Ammopiptanthus mongolicus Maxim. Journal of Desert Research (中国沙漠), 20,320-322. (in Chinese with English abstract)

Wang XP(王新平), Li XR(李新荣), Kang ES(康尔泗), Zhang JG(张景光), Zhou HY (周海燕), Yang SX(杨诗秀), Lei ZD (雷志栋) (2003). The infiltration and redistribution of precipitation in revegetated sand dunes in the Tengger Desert, Shapotou, China. Acta Ecologica Sinica (生态学报), 23, 1234- 1241. (in Chinese with English abstract)

Yang QH(杨期和), Ge XJ(葛学军), Ye WH(叶万辉), Deng X (邓雄), Liao FL(廖富林) (2004). Charactstics of Ammopiptanthus nanus seed and factors affecting its germintion. Acta Phytoecologica Sinica (植物生态学报), 28,651 - 656. (in Chinese with English abstract)

Ye CF (叶常丰), Dai XW (戴心维) (1994). Seeds (种子学). China Agriculture Press, Beijing. (in Chinese)

Zhang T(张涛), Jiang ZR(蒋志荣) (1987). Study on introduction and cultivation test of Ammopiptanthus mongolicus Maxim. Journal of Desert Research (中国沙漠), 7 (3),41 - 47. (in Chinese with English abstract)

Zhao CM, Wang GX (2002) . Effects of drought stress on the photoprotection in Ammopiptanthus mongolicus leaves. Acta Botanica Sinica (植物学报), 44,1309-1313. 